\title{
General Psychiatry Knowledge and prevalence of energy drinks consumption in Shanghai, China: a cross-sectional survey of adolescents
}

\author{
Ruyan Luo, ${ }^{1}$ Rao Fu, ${ }^{1}$ Lu Dong, ${ }^{2}$ Zheyi Du, ${ }^{1}$ Wei Sun, ${ }^{3}$ Min Zhao ${ }^{(0)},{ }^{1}$ Jiang Du ${ }^{1}$
}

To cite: Luo R, Fu R, Dong L, et al. Knowledge and prevalence of energy drinks consumption in Shanghai, China: a cross-sectional survey of adolescents. General Psychiatry 2021;34:e100389. doi:10.1136/ gpsych-2020-100389

$\mathrm{RL}$ and RF contributed equally.

Received 11 October 2020 Revised 19 March 2021 Accepted 13 April 2021

\section{Check for updates}

(c) Author(s) (or their employer(s)) 2021. Re-use permitted under CC BY-NC. No commercial re-use. See rights and permissions. Published by BMJ.

${ }^{1}$ Shanghai Mental Health Center Shanghai, China

${ }^{2}$ RAND Corp, Santa Monica, California, USA

${ }^{3}$ Community Health Service Center of Jiangning Road,

Shanghai, China

Correspondence to Dr Jiang Du; dujiangdou@163.com

Dr Min Zhao; drminzhao@gmail.com

\section{ABSTRACT}

Background In recent years, energy drinks (EDs) have been widely used among young people around the world. The extensive use of EDs also affects the sleep and exercise of adolescents.

Aims This study aimed to investigate the consumption of EDs, the knowledge, attitude towards EDs and associated factors of EDs consumption among adolescents in Shanghai, China.

Methods A total of 4608 adolescents completed a self-administered questionnaire assessing EDs use history, knowledge and attitude towards EDs. Adolescent Self-rating Life Events Checklist (ASLEC) was used to assess their life events. All participants were divided into two groups based on whether they used them or not. t-test and $\chi^{2}$ test were used to compare the differences between the two groups, and binary logistic regression analysis was used to investigate the related factors for EDs consumption.

Results $70.5 \%$ of the participants reported having ever used EDs. The main avenues to getting information on EDs were from advertisements. $67.56 \%$ of them believed that EDs had adverse effects on health. 22.09\% of the participants and $31.55 \%$ of their parents took a negative attitude towards EDs. Compared with the nonconsumption group, participants in the consumption group were likely to be male, with older age, identified EDs more correctly and did not believe EDs had adverse effects, with more positive attitude and higher ASLEC score. Logistic regression results showed that gender, age, attitude of parents and themselves, knowledge of EDs and ASLEC score significantly predicted EDs consumption.

Conclusion EDs consumption was popular among adolescents in Shanghai, and the tailored intervention programmes need to be developed based on the characteristics of adolescents.

\section{BACKGROUND}

Energy drinks (EDs) have become increasingly popular in recent years, and the EDs market has grown at a rapid speed in China since the 1990s. ${ }^{1}$ In the USA, the sales of EDs continue increasing from 2.3 billion bottles in 2005 to 6 billion bottles in 2010. Sales were reportedly nearing $\$ 50$ billion worldwide in $2015 .^{2}$ EDs are a generic term for soft drinks, including carbonated beverages, fruit and vegetable juices, bottled water, sports drinks and ready-to-drink coffee. ${ }^{3}$ The ingredients of EDs vary depending on the brands, but most contain high doses of caffeine, sugar and the amino acid taurine. ${ }^{4}$ EDs are aggressively marketed to adolescents and young adults as providing mental alertness, increasing energy, elevating mood and relief from fatigue. ${ }^{56} \mathrm{~A}$ survey conducted among college students in the USA revealed that more than $50 \%$ of students consumed more than one ED each month. A web-based survey conducted from 10 universities revealed that $24 \%$ of them had consumed EDs with alcohol within the last 30 days. $^{7}$ Two studies conducted in China revealed the consumption of EDs was $50.1 \%$ (lifetime) in mainland $\mathrm{China}^{8}$ and $24.8 \%$ in the past 30 days in Taiwan. ${ }^{9}$

Several EDs are available on the Chinese market, such as Red Bull and Monster. These EDs are available and easily purchased on the market or at small retail grocery. ${ }^{10}$ Due to the easy access, adolescents are consuming more and more EDs. Caffeine, as the key ingredient in EDs, has stimulating effects that can enhance mental and physical performance and has been associated with improved alertness and concentration. ${ }^{6}$ 11-13 Higher caffeine consumption is associated with adverse effects, including irritability and palpitations, sleep interruptions ${ }^{14}{ }^{15}$ and cardiovascular complications. More than that, the consumption of EDs among adolescents has been linked to high-risk behaviours such as smoking, drinking, illicit drug use, game overuse and unsafe sexual practices. ${ }^{16} 17$ Using EDs mixed with alcohol and related harmfulness also have been widely reported. A study conducted in Taiwan reported that $15 \%$ of adolescents had ever mixed EDs with alcohol $^{9}$, and a possible reason of mixed consumption was due to the false perception that the caffeine in the EDs will prevent sleeping from alcohol and allow the people to drink more alcohol, consequently leading to alcohol-related adverse events. ${ }^{9} 18$ There 
are other adverse effects with ED consumption, including poor academic performance and slowing brain development. For example, an animal study indicated that caffeine influenced the activities of the enzymes and neurotransmitters in the brain and altered brain chemistry relative to the tested enzymes and neurotransmitters, which may affect neuronal structure and function. ${ }^{19}$

Factors influencing adolescents' consumption of EDs have been reported, in addition to easy to access and psychoactive function of EDs, other factors including characteristics of adolescents and their knowledge, and attitude towards ED consumption. Studies suggested that consumption of EDs were associated with higher impulsivity and risk-taking behaviours. ${ }^{20-22}$ Adolescents tend to pursue novelty and take risks, which puts them more at risk to use EDs.

So far, very few studies have addressed ED consumption among Chinese students, and there was no report on the ED consumption of middle and high school students. To address this gap, we conducted a survey of adolescents consuming EDs in Shanghai, with the aim to investigate the consumption of EDs in this sample of adolescents and further explore the factors influencing ED consumption.

\section{METHODS}

\section{Participants and procedures}

Shanghai has over 1 million students distributed in 16 districts. Six representative districts were selected by the Shanghai Municipal Education Commission based on the education resources, including: (1) two districts (Chongming and Fengxian) located in a rural area; (2) two districts (Huangpu and Jing'an) located in the city center, and (3) two districts (Minhang and Pudong) with lots of migrant workers and limited education resources. The sample selected for this study is representative of the target population.

One middle school and one high school were selected from each district, and 100 students were randomly selected from grade 8 , grade 9 , grade 11 and grade 12 based on the lists provided by the students' affairs office. In total, 12 schools with 4724 students were invited to participate in this anonymous survey, and there were 4608 valid questionnaires returned (figure 1). Before the survey, research staff explained the study purpose to the students and emphasised that their participation was voluntary and declining to participate could not affect their privileges in

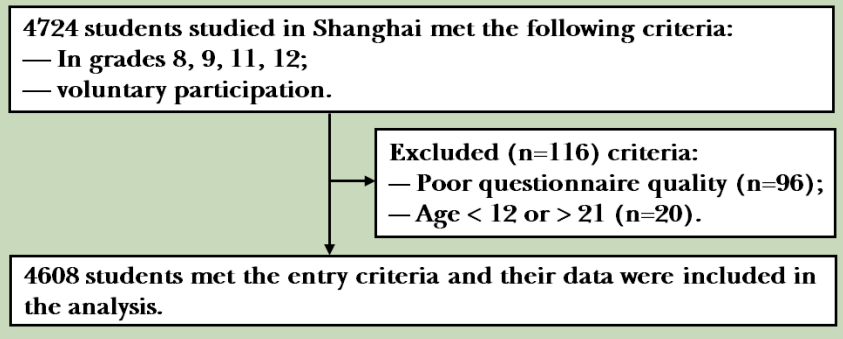

Figure 1 Flowchart for the enrolment. schools. WeChat-based informed consents were received from participants and their parents.

\section{Measures}

Demographics of students were collected including gender, age and district.

\section{EDs knowledge}

Two items were used to evaluate their ED related knowledge: (1) ability to distinguish the EDs. Participants were required to distinguish all the EDs from six beverage brands; (2) participants were required to answer whether the EDs were harmful to their health with responses 'Yes', 'No' and 'Not Sure'.

\section{Attitudes towards EDs}

Two items were used to assess participants' attitude towards ED consumption with the responses of 'Positive', 'Negative' or 'Neutral': (1) what do you think about EDs consumption? and (2) what is your parents' attitude towards EDs consumption?

\section{EDs consumption history}

ED consumption history was collected via self-reported questions: (1) have you ever used EDs before? and (2) how often do you use it? ('Occasionally', 'Often' or 'Always').

\section{Adolescent Self-rating Life Events Checklist}

ASLEC is a self-reported questionnaire developed by Xianchen Liu which was used to measure the severity of life stress experienced during the past year of adolescence. It consists of 27 negative events that may bring psychological responses to adolescents. This questionnaire has been widely used in China and with good reliability and validity (Cronbach's $\alpha=0.92){ }^{8}$

\section{Statistical analyses}

To explore the factors that influence EDs consumption, all participants were divided into the drinking group and the non-drinking group based on whether they consumed EDs or not. Statistical Product and Service Solutions V.23.0 was used to conduct the statistical analyses. Continuous data were presented as the mean and SD. Between-group differences for continuous variables were evaluated using t-test. Between-group comparisons for categorical variables were performed using the $\chi^{2}$ test or Fisher's exact test when appropriate. In order to further understand the related factors affecting the consumption of EDs by adolescents, the previously mentioned statistical variables with significant differences were used as independent variables, and the consumption of EDs was taken as the dependent variable for binary logistic regression analysis. Covariates included gender, age, grade, knowledge, attitude of participant and their parents and ASLEC. Statistical significance was determined at $\mathrm{p}<0.05$.

\section{RESULTS}

\section{Demographic and EDs consumption}

Sample demographics were summarised in table 1. Overall, $47.46 \%$ of participants were male. The mean (SD) age was 
Table 1 Demographic information, knowledge and attitude towards EDs

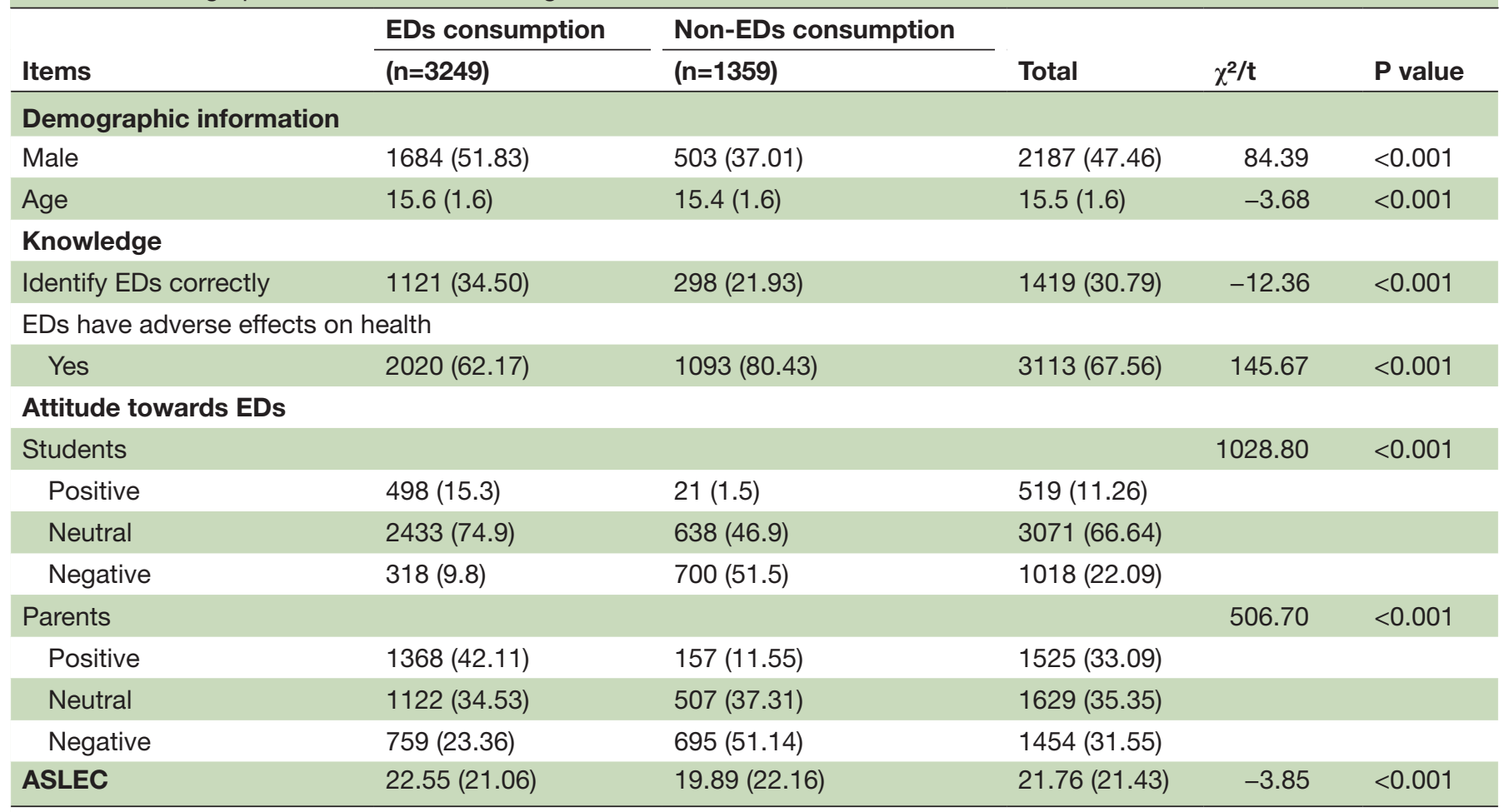

SEs in the parentheses.

ASLEC, Adolescent Self-rating Life Events Checklist; EDs, energy drinks.

15.5 (1.6) years. More than three quarters $(88.6 \%)$ of participants reported that they heard about EDs before, and 93.3\% of them knew about EDs from advertisements. Other channels for obtaining information on EDs were from peers $(39.5 \%)$, websites $(38.7 \%)$, magazines $(34.2 \%)$, teleplays (27.2\%) and newspapers (22.2\%).

A total of 3249 (70.5\%) participants had ever consumed EDs. A percentage of 30.8 of the participants were able to identify the EDs correctly. A percentage of 67.56 of participants believed that EDs had adverse effects on health. Only $22.09 \%$ of the participants and $31.55 \%$ of their parents held negative attitudes towards EDs. Compared with the non-consumption group, participants of the ED consumption group were more likely to be male, with older age and higher grades. Regarding the knowledge about EDs, the consumption group could identify EDs more correctly $(t=-12.36, \mathrm{p}<0.001)$. Compared with the non-ED consumption group, participants in the consumption group were more likely to believe that EDs had no adverse effects on health $\left(\chi^{2}=145.67, \mathrm{p}<0.001\right)$. Participants in the consumption group and their parents had less negative attitudes (students: $\chi^{2}=1028.80, \mathrm{p}<0.001$; parents: $\chi^{2}=506.70$, $\mathrm{p}<0.001)$ and had higher ASLEC scores, compared with the non-consumption group $(\mathrm{t}=-3.85, \mathrm{p}<0.001)$. Reasons for ED consumption were 'relieving fatigue' $(53.25 \%)$, 'just for fun' $(38.78 \%)$, 'being influenced by peers' (21.11\%), 'staying up late' (16.31\%), 'taking before the exam' (11.27\%) and 'improving negative emotions' (6.12\%). The side effects of consuming EDs were 'heart palpitations' (13.2\%), 'insomnia' (4.19\%) and 'dizziness' (2.22\%) (table 2).

The results of logistic regression analysis were shown in the table 3. The Cox \& Snell R square value is 0.253 , and Nagelkerke R square value is 0.360 . Male adolescents, compared with female adolescents, were more likely to belong to the EDs consumption group $(\mathrm{OR}=1.61,95 \% \mathrm{CI}$ : 1.38 to 1.88 ). Younger participants, compared with older participants, were more likely to use $\mathrm{EDs}(\mathrm{OR}=0.92$, 95\% CI: 0.88 to 0.97$)$. Level of identifying EDs correctly were significant factors associated with ED consumption $(\mathrm{OR}=1.42,95 \%$ CI: 1.32 to 1.53$)$. Participants who thought EDs had adverse effects on health, in contrast to those who thought EDs had no adverse effects, were less likely to use EDs (OR=0.79, 95\% CI: 0.66 to 0.94$)$. Attitudes of parents and adolescents towards EDs were significantly influencing ED consumption. Participants with positive $(\mathrm{OR}=23.81,95 \%$ CI: 14.81 to 38.25$)$ and neutral attitudes ( $\mathrm{OR}=6.02,95 \%$ CI: 5.07 to 7.14 ) towards EDs were more likely to be in EDs consumption group than those with negative attitudes. The same was true of parental attitudes (positive: OR=4.01, 95\% CI: 3.19 to 5.04; neutral: $\mathrm{OR}=1.38,95 \%$ CI: 1.14 to 1.66$)$. In addition, participants' ASLEC score was a significant predictor; participants with higher ASLEC scores were more likely to use EDs (OR=1.004, 95\% CI: 1.00 to 1.01$)$. 
Table 2 The reasons and side effects of EDs consumption

\begin{tabular}{|cc|}
\hline Have you ever heard of EDs? (N=4608) & $N(\%)$ \\
\hline Yes & $4083(88.6)$ \\
\hline No & $525(11.4)$ \\
\hline Access to EDs information(N=4083) & \\
\hline Advertisement & $3810(93.3)$ \\
\hline Peers & $1613(39.5)$ \\
\hline Websites & $1579(38.7)$ \\
\hline Magazines & $1398(34.2)$ \\
\hline Teleplays & $1109(27.2)$ \\
\hline Newspapers & $906(22.2)$ \\
\hline Reason for using EDs (N=3249) & $1730(53.25)$ \\
\hline Relieve fatigue & $1260(38.78)$ \\
\hline Just for fun & $686(21.11)$ \\
\hline Influenced by peers & $530(16.31)$ \\
\hline Stay up late & $366(11.27)$ \\
\hline Take before the exam & $199(6.12)$ \\
\hline Improve negative emotions & $72(2.22)$ \\
\hline Side effects (N=3249) & $429(13.20)$ \\
\hline Cardiopalmus & $136(4.19)$ \\
\hline Insomnia & \\
\hline Dizziness & \\
\hline
\end{tabular}

SEs in the parentheses.

EDs, energy drinks.

\section{DISCUSSION}

\section{Main findings}

To the best of our knowledge, this is the first study to explore EDs consumption in Chinese adolescents. Some of the studies assessed the amount of the EDs consumed in the past month, but they used different definitions of EDs. ${ }^{13} 2324$ Even with that, such a high consumption rate reminded us that more attention needs to be paid to this population.
Similar to other studies, advertisements were reported as the main avenue to getting EDs, and major reasons for ED use were keeping awake and relieving fatigue. ${ }^{2325-27} \mathrm{In}$ China, TV has become the main entertainment medium, and most of the students' spare time was spent watching TV. As a result, the content of advertisements has a great impact on students' lifestyle. ${ }^{28}$ Moreover, compared with other countries, middle and high school students in China faced more academic pressure, so they were more likely to use EDs to relieve fatigue. Although most of the students $(67.56 \%)$ knew that EDs could have adverse health effects, the individuals who did not use EDs were more likely to hold this viewpoint, which meant ED consumption was influenced by students' cognition.

According to the behavioural change theory, attitude also played an important role in determining behaviour change. As the results of the current study showed, a small number of students and their parents held negative attitudes towards EDs consumption. The previous literature reported that parents' restrictions on adolescent ED use are related to their personal drinking behaviour. ${ }^{22}$ In China, from the viewpoint of parents, academic performance is a major factor that determines the children's future life. Due to the limited knowledge of EDs, or influenced by commercial advertisements, parents believe that EDs can help children relieve fatigue and enhance their attention; therefore they may hold a positive attitude towards EDs. The current study could not provide data of parents' knowledge level on EDs. However, under the current educational environment, we assumed that this was an important reason, and it reminded us that both parents and children, not children alone, should be the primary target of interventions. Knowledge or attitudes are defined as 'prerequisites' for enacting a health behaviour, so the intervention programme aiming to improve their knowledge is also important. ${ }^{29}$

Negative emotion is a risk factor for ED consumption since previous studies have reported that psychoactive substances, such as caffeine, could be used to handle

\begin{tabular}{lccccr}
\hline Table 3 & Logistic regression analysis of EDs consumption versus non-EDs consumption & & \\
\hline Items & $\boldsymbol{\beta}$ & $\mathbf{S E}$ & $\mathbf{O R}$ & $\mathbf{9 5 \%} \mathbf{C l}$ & P value \\
\hline Male & 0.48 & 0.08 & 1.61 & 1.38 to 1.88 & $<0.001$ \\
Age & -0.08 & 0.03 & 0.92 & 0.88 to 0.97 & 0.003 \\
Correctly identify & 0.35 & 0.04 & 1.42 & 1.32 to 1.53 & $<0.001$ \\
Whether there are adverse effects? (Yes) & -0.24 & 0.09 & 0.79 & 0.66 to 0.94 & 0.010 \\
Students attitude (negative) & & & & & $<0.001$ \\
$\quad$ Neutral & 1.80 & 0.09 & 6.02 & 5.07 to 7.14 & $<0.001$ \\
$\quad$ Positive & 3.17 & 0.24 & 23.81 & 14.81 to 38.25 & $<0.001$ \\
Parental attitude (negative) & & & & & $<0.001$ \\
$\quad$ Neutral & 0.32 & 0.09 & 1.38 & 1.14 to 1.66 & 0.001 \\
$\quad$ Positive & 1.39 & 0.12 & 4.01 & 3.19 to 5.04 & $<0.001$ \\
ASLEC & 0.004 & 0.002 & 1.004 & 1.00 to 1.01 & 0.047
\end{tabular}

ASLEC, Adolescent Self-rating Life Events Checklist; EDs, energy drinks. 
negative emotions. ${ }^{13} 3031$ In the study, we found that adolescents with more ED consumption had higher ASLEC scores. We assume that student may use EDs to deal with negative emotions. As has been demonstrated in other cross-sectional studies, our study also demonstrated that male adolescents had a markedly higher level of ED consumption than female adolescents. The reasons may be that men engage in more physical exercise compared with women and are more likely to be attracted by sportsrelated EDs. ${ }^{26}{ }^{30}$ In addition, in interviews with middle school teachers, we found that students had limited knowledge about EDs. It is necessary to strengthen the publicity and education work of relevant departments in the future and improve the knowledge level of parents and students at the same time.

\section{LIMITATIONS}

Several limitations should be noted. First, we relied on selfreport data, which may be subject to recall bias. Second, we did not collect substance use data as well as physical and mental state information for the adolescents, so we could not evaluate the association between EDs consumption and substance use. Third, the participants cannot represent other regions of China. Future studies should use qualitative and quantitative methods to examine the influencing factors of ED consumption. Longitudinal studies should examine the long-term impact of using EDs on adolescents.

\section{IMPLICATIONS}

In summary, this study surveyed the extent of EDs consumption among adolescents in China and assessed the impact of sociodemographic knowledge and attitudes on EDs consumption. The findings of the study indicated that ED consumption must be considered by national public health authorities, and a focus on adolescents at risk for ED consumption should be established in the healthcare system, as well as in schools. Schools can play a significant role in enhancing students' knowledge regarding EDs. Thus, comprehensive school-based intervention programmes, such as the Student Assistance Program, should be implemented to influence adolescents' behaviours.

Acknowledgements We are grateful for all participants who completed the survey despite their heavy workload.

Contributors RL, RF, JD and MZ prepared the research proposal and guided the study implementation. All authors revised study and assessments methods. All authors revised the work critically for important intellectual content.

Funding This work was supported by Shanghai Clinical Research Center for Mental Health (19MC1911100), Program of Science and Technology Innovation Plan in Shanghai (18411961200), Shanghai Intelligent Engineering Technology Research Center for Addiction and Rehabilitation (19DZ2255200), the National Nature Science Foundation (U1502228, 81771436, 81871045), Shanghai Key Laboratory of Psychotic Disorders (13DZ2260500), Program of Shanghai Science and Technology Committee (19411969200) and Shanghai Mental Health Center Clinical Research Center Project (CRC2017YB04).

Competing interests None declared.
Patient consent for publication Not required.

Ethics approval The study protocol was approved by the institutional review board at Shanghai Mental Health Center (IRB No. 2011-06).

Provenance and peer review Not commissioned; externally peer reviewed.

Data availability statement № data are available.

Open access This is an open access article distributed in accordance with the Creative Commons Attribution Non Commercial (CC BY-NC 4.0) license, which permits others to distribute, remix, adapt, build upon this work non-commercially, and license their derivative works on different terms, provided the original work is properly cited, appropriate credit is given, any changes made indicated, and the use is non-commercial. See: http://creativecommons.org/licenses/by-nc/4.0/.

ORCID iD

Min Zhao http://orcid.org/0000-0001-8382-3050

\section{REFERENCES}

$1 \mathrm{~J} \mathrm{~W}$. Current situation and future development direction of energy drinks market. Food and Fermentation Industries 2007;4:101-6.

2 Utter J, Denny S, Teevale T, et al. Energy drink consumption among New Zealand adolescents: associations with mental health, health risk behaviours and body size. J Paediatr Child Health 2018;54:279-83.

3 Fontinelle A. The energy drinks industry. New York, NY, 2015. Available: http://www.investopedia.com/articles/investing/ 022315/ energy-drinks-industry.asp [Accessed 23 Mar 2020].

4 Curran CP, Marczinski CA. Taurine, caffeine, and energy drinks: reviewing the risks to the adolescent brain. Birth Defects Res 2017; 109:1640-8.

5 O'Brien MC, McCoy TP, Rhodes SD, et al. Caffeinated cocktails: energy drink consumption, high-risk drinking, and alcoholrelated consequences among college students. Acad Emerg Med 2008;15:453-60.

6 Sepkowitz KA. Energy drinks and caffeine-related adverse effects. JAMA 2013;309:243-4.

7 Marczinski CA. Alcohol mixed with energy drinks: consumption patterns and motivations for use in U.S. college students. Int $J$ Environ Res Public Health 2011;8:3232-45.

8 Hu C, Wang L. Relationship between energy drink consumption and sensation seeking in college students. Chinese Journal of Health Education 2019;35:1575-8.

9 Chang Y-J, Peng C-Y, Lan Y-C. Consumption of energy drinks among undergraduate students in Taiwan: related factors and associations with substance use. Int J Environ Res Public Health 2017;14. doi:10.3390/ijerph14090954. [Epub ahead of print: 24 Aug 2017].

10 Hashem KM, He FJ, MacGregor GA. Cross-sectional surveys of the amount of sugar, energy and caffeine in sugar-sweetened drinks marketed and consumed as energy drinks in the UK between 2015 and 2017: monitoring reformulation progress. BMJ Open 2017;7:e018136.

11 McLellan TM, Riviere LA, Williams KW, et al. Caffeine and energy drink use by combat arms soldiers in Afghanistan as a countermeasure for sleep loss and high operational demands. Nutr Neurosci 2019;22:768-77.

12 Rahamathulla MP. Prevalence, side effects and awareness about energy drinks among the female university students in Saudi Arabia. Pak J Med Sci 2017;33:347-52.

13 Souza DB, Del Coso J, Casonatto J, et al. Acute effects of caffeinecontaining energy drinks on physical performance: a systematic review and meta-analysis. Eur J Nutr 2017;56:13-27.

14 McLellan TM, Lieberman HR. Do energy drinks contain active components other than caffeine? Nutr Rev 2012;70:730-44

15 Roehrs T, Roth T. Caffeine: sleep and daytime sleepiness. Sleep Med Rev 2008;12:153-62.

16 Larson N, Laska MN, Story M, et al. Sports and energy drink consumption are linked to health-risk behaviours among young adults. Public Health Nutr 2015;18:2794-803.

17 Poulos NS, Pasch KE. Energy drink consumption is associated with unhealthy dietary behaviours among College youth. Perspect Public Health 2015;135:1757913914565388.

18 Peacock A, Bruno R, Martin FH. The subjective physiological, psychological, and behavioral risk-taking consequences of alcohol and energy drink co-ingestion. Alcohol Clin Exp Res 2012;36:2008-15.

19 Owolabi JO, Olatunji SY, Olanrewaju AJ. Caffeine and cannabis effects on vital neurotransmitters and enzymes in the brain tissue of juvenile experimental rats. Ann Neurosci 2017;24:65-73. 
20 Azagba S, Langille D, Asbridge M. An emerging adolescent health risk: caffeinated energy drink consumption patterns among high school students. Prev Med 2014;62:54-9.

21 Terry-McElrath YM, O'Malley PM, Johnston LD. Energy drinks, soft drinks, and substance use among United States secondary school students. J Addict Med 2014;8:6-13.

22 Scalese M, Denoth F, Siciliano V, et al. Energy drink and alcohol mixed energy drink use among high school adolescents: association with risk taking behavior, social characteristics. Addict Behav 2017;72:93-9.

23 Higgins JP, Babu K, Deuster PA, et al. Energy drinks: a contemporary issues paper. Curr Sports Med Rep 2018;17:65-72.

24 Park S, Lee Y, Lee JH. Association between energy drink intake, sleep, stress, and suicidality in Korean adolescents: energy drink use in isolation or in combination with junk food consumption. Nutr $J$ 2016;15:87.

25 Khamis Ragab Ibrahim N, Iftikhar R, Murad M, et al. Energy drinks consumption amongst medical students and interns from three colleges in Jeddah, Saudi Arabia. J Food Nutr Res 2014;2:174-9.

$26 \mathrm{~K}-\mathrm{K}$ K, Kim M-H, Lee J-H. Intake status and perception of energy drinks according to the gender and obesity of some university students in Chungnam Province. Korean J Food Nutrition 2019;32:167-78.

27 Qtait M, Alarab S. Energy drink usage and effect among university students in a Polytechnic Palestine. Am J Food Sci Health 2020;6:89-94.

28 Ding L, Newman IM, Buhs ES, et al. Influence of Peer Pressure and Self-Efficacy for Alcohol Self-Regulation on Chinese University Physical Education Students' Drinking Behaviors. Advances in Physical Education 2018;08:46-57.

29 Fisher JD, Fisher WA, Bryan AD, et al. Information-motivationbehavioral skills model-based HIV risk behavior change intervention for inner-city high school youth. Health Psychol 2002;21:177-86.

30 Mansour B, Amarah W, Nasralla E, et al. Energy drinks in children and adolescents: demographic data and immediate effects. Eur $J$ Pediatr 2019;178:649-56.

31 Subaiea GM, Altebainawi AF, Alshammari TM. Energy drinks and population health: consumption pattern and adverse effects among Saudi population. BMC Public Health 2019;19:1539.

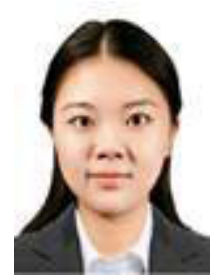

Ruyan Luo obtained a bachelor's degree from Sichuan University in China in 2019. In the same year, she began her postgraduate studies at the Department of Substance and Addiction in the Shanghai Mental Health Center, Shanghai Jiao Tong University School of Medicine, Shanghai, China. Her research interests include substance abuse and addiction.

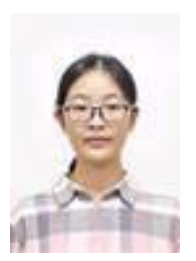

Rao Fu obtained a bachelor's degree from Jilin University in China in 2019. In the same year, she began her postgraduate studies at the Department of Substance and Addiction in the Shanghai Mental Health Center, Shanghai Jiao Tong University School of Medicine, Shanghai, China. Her research interests include substance abuse and addiction. 